\title{
Taxonomic Status of the Sandperch Percis caudimaculatum and Validity of Parapercis ommatura (Actinopterygii: Perciformes: Pinguipedidae)
}

\author{
Hisashi Imamura ${ }^{1}$ and Tetsuo Yoshino ${ }^{2}$ \\ ${ }^{1}$ The Hokkaido University Museum, 3-1-1 Minato-cho, Hakodate, Hokkaido, 041-8611 Japan \\ E-mail: imamura@museum.hokudai.ac.jp \\ ${ }^{2}$ Department of Marine Sciences, Faculty of Science, University of the Ryukyus, 1 Senbaru, \\ Nishihara, Okinawa, 903-0213 Japan \\ E-mail:b985005@sci.u-ryukyu.ac.jp
}

(Received 18 August 2006; Accepted 8 February 2007)

\begin{abstract}
There are no significant morphological differences between the four syntypes of the pinguipedid sandperch Percis caudimaculatum Haly, 1875 and the holotype of Parapercis ommatura Jordan and Snyder, 1902. The former nominal taxon is thus a subjective senior synonym of the latter, but it is also a junior homonym of Percis caudimaculata Rüppell, 1838, and thus invalid. In addition, Rüppell's taxon, now assigned to the genus Parapercis, has been recognized as a junior synonym of Parapercis hexophtalma (Cuvier in $\mathrm{Cu}-$ vier and Valenciennes, 1829). Parapercis ommatura, being the first available junior synonym of Parapercis caudimaculata (Haly, 1875), becomes the valid name for the species.
\end{abstract}

Key Words: Actinopterygii, Perciformes, Pinguipedidae, Parapercis ommatura, synonym, homonym, nomenclature.

\section{Introduction}

The pinguipedid fish Percis caudimaculatum Haly, 1875 was briefly described from four specimens collected from northern China without illustrations (Haly 1875). De Beaufort and Chapman (1951) placed it in the synonymy of Parapercis hexophtalma (Cuvier in Cuvier and Valensiennes, 1829) without explanation, and they were followed by Cantwell (1964). Our detailed examination of the four syntypes of Percis caudimaculatum has revealed that it is not conspecific with Parapercis hexophtalma, but is a senior synonym of Parapercis ommatura Jordan and Snyder, 1902 (q. v.). The latter is known from southern Japan, Korea, northern China, and the South China Sea (e.g., Cantwell 1964; Shimada 2002). The purpose of this study is to show the basis for the synonymy of Percis caudimaculatum and Parapercis ommatura and the nomenclatural validity of the latter name. 


\section{Materials and Methods}

Counts and measurements were made according to Hubbs and Lagler (1958) and Randall (1984). Where disagreements were found between these methods, Randall's methods were used. Specimen lengths are expressed as standard length. The number of vertical cheek scales was counted in the scale row running posteroventrally from the middle of the lower margin of the eye. Measurements were made with calipers to the nearest $0.1 \mathrm{~mm}$. Institutional abbreviations follow Leviton et al. (1985).

Material examined. Parapercis ommatura (16 specimens): SU 6540 (presently deposited at CAS), holotype $(80.2 \mathrm{~mm})$, Nagasaki, Japan, date unknown; BMNH 1862.11.1.189-192, 4 syntypes of Percis caudimaculatum Haly, 1875 (67.2-83.9 mm), northern China, Yellow Sea, date unknown (synonymized herein); BSKU 61753, 1 specimen (64.5 mm), Yoshima, Kagawa, Japan, 30 April 1999; BSKU 81918, 1 specimen $(78.6 \mathrm{~mm})$, off Kochi, Japan $\left(33^{\circ} 28.40^{\prime} \mathrm{N}, 133^{\circ} 33.06^{\prime} \mathrm{E}\right.$ to $\left.33^{\circ} 28.57^{\prime} \mathrm{N}, 133^{\circ} 33.35^{\prime} \mathrm{E}\right)$, 13-15 $\mathrm{m}$ depth, 14 April 1994; BSKU 81924, 81925, 2 specimens $(85.3,85.5 \mathrm{~mm}$ ), off Kochi, Japan $\left(33^{\circ} 27.18^{\prime} \mathrm{N}, 133^{\circ} 32.52^{\prime} \mathrm{E}\right.$ to $\left.33^{\circ} 27.44^{\prime} \mathrm{N}, 133^{\circ} 33.02^{\prime} \mathrm{E}\right), 30 \mathrm{~m}$ depth, 4 September 1994; HUMZ 36462, 1 specimen $(78.1 \mathrm{~mm})$, data unknown; HUMZ 44569, 1 specimen $(90.5 \mathrm{~mm})$, off Onomichi, Hiroshima, Japan, August 1930; HUMZ 69519, 1 specimen (101.9 mm), Toushi, Shima, Mie, Japan, date unknown; NSMT-P 799, 1 specimen $(69.8 \mathrm{~mm})$, Wakanoura, Wakayama, Japan, 1889; NSMT-P 2675, 1 specimen $(89.9 \mathrm{~mm})$, Takamatsu, Kagawa, Japan, August 1959; NSMT-P 52960, 1 speci-

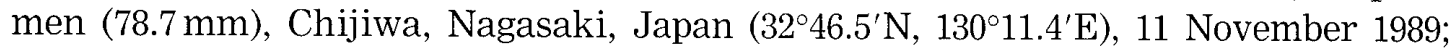
NSMT-P 53589, 1 specimen $(87.0 \mathrm{~mm})$, Aba Fishing Port, Nagasaki, Japan $\left(32^{\circ} 46.1^{\prime} \mathrm{N}\right.$, $\left.1290^{\circ} 56.6^{\prime} \mathrm{E}\right), 18$ December 1989.

Comparative material. Parapercis hexophtalma (4 specimens): ZMB 517, holotype (159.3 mm), Massawa, Eritrea, Red Sea, date unknown; HUMZ 165320, 165335, 2 specimens (159.3, 177.3 mm), Al-Wajh, Red Sea, fishing, 25 June 1999; HUMZ 16319, 1 specimen $(172.7 \mathrm{~mm})$, island off Al-Wajh, Red Sea, fishing, 17 June 1999.

\section{Results and Discussion}

\section{Taxonomic status of Percis caudimaculatum}

After examination of the four syntypes of Percis caudimaculatum, the following diagnostic characters were confirmed: 22 soft dorsal fin rays, 18 soft anal fin rays, spinous dorsal fin connected by membrane to base of first soft dorsal ray, and dark brown spot on upper portion of caudal fin base (Fig. 1). Parapercis hexophtalma usually has 21 soft dorsal fin rays and 17 anal fin rays, the last dorsal fin spine connected to the first soft dorsal ray opposite the tip of the last spine, and a very large black blotch in the center of the caudal fin (e.g., Randall 1995; this study). Therefore, the synonymy of Percis caudimaculatum and Parapercis hexophtalma is not supported.

On the other hand, the characters of Percis caudimaculatum agree well with those of Parapercis ommatura. Comparison of the syntypes of Percis caudimaculatum and the holotype of Parapercis ommatura revealed no significant differences in counts and proportions; however, there were slight differences in the numbers 
of upper gill rakers, lateral line scales, and scales between the anal fin origin and lateral line (three or four upper gill rakers, 58 lateral line scales, and 13 scales between the anal fin origin and lateral line in Percis caudimaculatum syntypes vs. one, 56, and 10, respectively, in the Parapercis ommatura holotype (Table 1). Nontype specimens identical with Parapercis ommatura (and also Percis caudimaculatum) examined for this study bear one to five upper gill rakers and 5658 lateral line scales; numbers that fill the gap in these counts between the type material of these two nominal species. In addition, Parapercis ommatura is reported to have either two or three upper gill rakers (e.g., Kamohara 1960; Okamura 1984) and 56-60 lateral line scales (e.g., Okamura 1984; Shimada 2002). The five available nontype specimens with scales in the abdominal region had 12-14 scales between the anal fin origin and lateral line, but Cantwell (1964) reported Parapercis ommatura as having scale counts in the range of 10 (or 11) to 12 (or 13). Therefore, we consider Percis caudimaculatum and Parapercis ommatura to be conspecific.

\section{Validity of Parapercis ommatura}

From the above-mentioned results, Percis caudimaculatum Haly, 1875 is a senior synonym of Parapercis ommatura. It is more proper to refer to it as Parapercis caudimaculata (Haly, 1875), owing to the following reasons: (1) the pinguipedid genus Percis Bloch and Schneider, 1801 is invalid because of being preoccupied by the agonid genus Percis Scopoli, 1777, and thus was replaced by Parapercis Bleeker, 1863; and (2) the gender of Parapercis is feminine (see Eschmeyer 1998).

This is a moot point, however, for Percis caudimaculata Haly, 1875 is a junior homonym of Percis caudimaculata Rüppell, 1838, and thus invalid. Rüppell's species, originally described based on specimens collected from the Red Sea, has also been synonymized under Parapercis hexophtalma (e.g., Günther 1860; de Beaufort and Chapman 1951; Cantwell 1964).

If a rejected junior homonym has one or more available and potentially valid synonyms, the oldest of these becomes the valid name of the taxon with its own authorship and date (International Commission on Zoological Nomenclature 1999, Art. 60.2). No other junior synonyms of Parapercis caudimaculata (Haly, 1875) except for Parapercis ommatura Jordan and Snyder, 1902 are known; therefore, we conclude that the latter is the valid name of the present species.

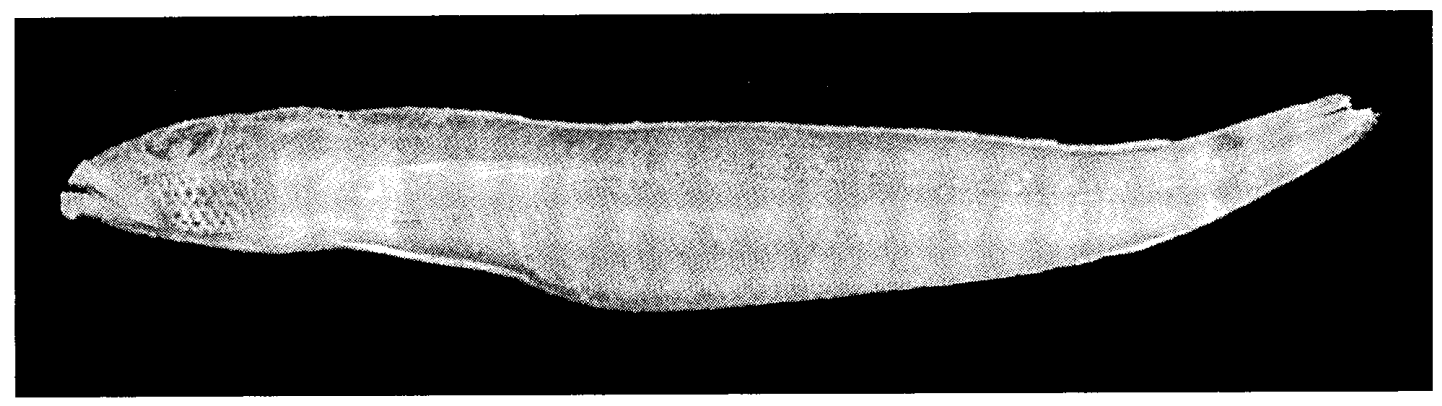

Fig. 1. Lateral view of the the largest syntype of Percis caudimaculatum Haly, 1875 (83.9 mm), BMNH 1862.11.1.189-192. 
Table 1. Counts and proportional measurements of Percis caudimaculatum Haly, 1875 and Parapercis ommatura Jordan and Snyder, 1902.

\begin{tabular}{|c|c|c|c|}
\hline & \multirow{2}{*}{$\frac{\text { Percis caudimaculatum }}{4 \text { syntypes }}$} & \multicolumn{2}{|c|}{ Parapercis ommatura } \\
\hline & & Holotype & 11 non-types \\
\hline SL (mm) & $67.2-83.9$ & 80.2 & $64.5-101.9$ \\
\hline \multicolumn{4}{|l|}{ Counts } \\
\hline Dorsal fin rays & $\mathrm{V}, 22(4)$ & $\mathrm{V}, 22$ & $\begin{array}{c}\mathrm{V}, 21-22(11) \\
\text { (usually } 22 \text { soft rays) }\end{array}$ \\
\hline Anal fin rays & $\mathrm{I}, 18(4)$ & $\mathrm{I}, 18$ & $\begin{array}{c}\text { I, } 18-19 \text { (11) } \\
\text { (usually } 18 \text { soft ravs) }\end{array}$ \\
\hline $\begin{array}{l}\text { Pectoral fin rays } \\
\text { (upper: unbr. + middle: } \\
\text { br.+ lower: unbr.) }\end{array}$ & $1+14+0=15(4)$ & $1+14+0=15$ & $1+14-15+0=15-16(11)$ \\
\hline Pelvic fin rays & $\mathrm{I}, 5(4)$ & I, 5 & I, $5(11)$ \\
\hline $\begin{array}{l}\text { Branched caudal fin rays } \\
\text { (up.+low.) }\end{array}$ & $7-8+7=14-15(3)$ & $8+7=15$ & $\begin{array}{l}7-8+7=14-15(8) \\
\text { (usually } 8+7=15 \text { ) }\end{array}$ \\
\hline Lateral line scales (LLS) & $58(4)$ & 56 & $56-58(10)$ \\
\hline $\begin{array}{l}\text { Scales between dorsal fin } \\
\text { origin and LLS }\end{array}$ & $4-6(2)$ & 4 & $5-6(8)$ \\
\hline $\begin{array}{l}\text { Scales between anal fin } \\
\text { origin and LLS }\end{array}$ & $13(1)$ & 10 & $12-14(5)$ \\
\hline $\begin{array}{l}\text { Scales anterior to dorsal } \\
\text { fin origin }\end{array}$ & $6-8(3)$ & 6 & $6-8(6)$ \\
\hline Vertical cheek scales & $6(3)$ & 6 & $6-7(9)$ \\
\hline Gill rakers & $3-4+7-9=12-13(2)$ & $1+7=8$ & $1-5+7-9=9-13(10)$ \\
\hline Canine teeth on lower jaw & $4(4)$ & 4 & 4-7 (10) (usually 4) \\
\hline \multicolumn{4}{|l|}{ Proportion as $\%$ SL } \\
\hline Head length & $26.4-27.5(4)$ & 26.1 & $25.6-27.6(11)$ \\
\hline Snout length & $6.6-7.7(4)$ & 7.1 & $6.6-7.9(11)$ \\
\hline Orbital diameter & $6.8-7.6(4)$ & 6.9 & $6.5-8.4(11)$ \\
\hline Interorbital width & $1.1-1.3(4)$ & 1.4 & $1.2-1.4(11)$ \\
\hline Upper jaw length & $7.9-8.5(4)$ & 8.1 & $7.7-8.8(11)$ \\
\hline Lower jaw length & $10.4-11.6(4)$ & 10.0 & $9.8-11.0(10)$ \\
\hline Predorsal length & $27.9-29.5(4)$ & 27.2 & $25.7-29.1(11)$ \\
\hline Preanal length & $44.6-48.4(4)$ & 44.3 & $45.0-47.1(11)$ \\
\hline Length of dorsal fin base & $62.8-69.5(4)$ & 65.1 & $63.0-69.0(11)$ \\
\hline Length of anal fin base & $49.0-49.4(4)$ & 48.0 & $45.5-49.3(11)$ \\
\hline Pectoral fin length & $18.3-21.9(4)$ & 18.5 & $17.9-20.6(11)$ \\
\hline Pelvic fin length & $18.9-22.9(4)$ & 19.5 & $19.3-21.7(9)$ \\
\hline Caudal fin length & $18.3-18.4(2)$ & 19.1 & $17.6-19.8(9)$ \\
\hline First dorsal spine length & $2.1-3.0(4)$ & 2.5 & $1.6-3.6(11)$ \\
\hline $\begin{array}{l}\text { Longest dorsal spine } \\
\text { (fourth) length }\end{array}$ & $7.5-9.7(4)$ & 8.5 & $8.1-11.3(8)$ \\
\hline Anal spine length & $3.5-5.5(4)$ & 5.2 & $4.5-6.0(11)$ \\
\hline
\end{tabular}

Number in parenthesis indicates that of examined specimens. 


\section{Acknowledgments}

We express our sincere thanks to J. Johnson (QM) for a critical reading of the manuscript. We are grateful to T. Iwamoto (CAS) for providing the morphological data from the holotype of Parapercis ommatura. We thank J. Maclaine (BMNH) for the loan of the syntypes of Haly's Percis caudimaculatum. Our thanks also go to P. Bartsch (ZMB), and H. Endo (BSKU) and K. Matsuura (NSMT), for providing the opportunities to examine the holotype of Parapercis hexophtalma and non-type specimens of Parapercis ommatura, respectively.

\section{References}

Cantwell, G. E. 1964. A revision of the genus Parapercis, family Mugiloididae. Pacific Science 18: 239-280.

de Beaufort, L. F. and Chapman, W. M. 1951. Fishes of the Indo-Australian Archipelago. IX. Percomorphi, Blennoidea. E. J. Brill, Leiden, xi $+484 \mathrm{pp}$.

Eschmyer, W. N. 1998. Catalog of Fishes, Vols 1-3. California Academy of Sciences, San Francisco, 2905 pp.

Günther, A. 1860. Catalogue of the Fishes in the British Museum. Vol. 2. Taylor \& Francis, London, xvi $+548 \mathrm{pp}$.

Haly, A. 1875. Descriptions of new species of fish in the collection of the British Museum. Annals and Magazine of Natural History, Including Zoology, Botany and Geology (4) 15: $268-270$.

Hubbs, C. L. and Lagler, K. F. 1958. Fishes of the Great Lakes region. Bulletin of the Cranbrook Institute of Science 26: 1-213, pls 1-44.

International Commission on Zoological Nomenclature 1999. International Code of Zoological Nomenclature. Fourth Edition. The International Trust for Zoological Nomenclature, London, xxix +306 pp.

Jordan, D. S. and Snyder, J. O. 1902. A review of the trachinoid fishes and their supposed allies found in the waters of Japan. Proceedings of the United States National Museum 24: 461-497.

Kamohara, T. 1960. A revision of the fishes of family Parapercidae found in the waters of Japan. Reports of the Usa Marine Biological Station 7(2): 1-14, pls 1-2.

Leviton, A. E., Gibbs, R. H. Jr., Heal, E. and Dawson, C. E. 1985. Standards in herpetology and ichthyology: part I. Standard symbolic codes for institutional resource collections in herpetology and ichthyology. Copeia 1985: 802-832.

Okamura, O. 1984. Parapercis ommatura Jordan et Snyder. Pp. 291-292, pl. 261G. In: Masuda, H., Amaoka, K., Araga, C., Uyeno, T., Yoshino, T. (Eds) The Fishes of the Japanese Archipelago. Tokai University Press, Tokyo, xxii +347 pp., 378 pls.

Randall, J. E. 1984. Two new Indo-Pacific mugiloidid fishes of the genus Parapercis. Freshwater and Marine Aquarium 7(12): 41-49.

Randall, J. E. 1995. Coastal Fishes of Oman. University of Hawaii Press, Honolulu, xiii +439 $\mathrm{pp}, 2$ maps.

Shimada, K. 2002. Pinguipedidae. Pp. 1059-1064, 1586-1587. In: Nakabo, T. (Ed.) Fishes of Japan with Pictorial Keys to the Species. English Edition. Tokai University Press, Tokyo, lxi +1749 pp. [In Japanese] 